\title{
Yellow nail syndrome: a review
}

\author{
Stéphane Vignes ${ }^{1 *}$ and Robert Baran ${ }^{2}$
}

\begin{abstract}
Yellow nail syndrome (YNS; OMIM 153300, ORPHA662) is a very rare disorder that almost always occurs after 50 years of age but a juvenile or familial form has also been observed. YNS is diagnosed based on a triad associating yellow nail discoloration, pulmonary manifestations (chronic cough, bronchiectasia, pleural effusion) and lower limb lymphedema. Chronic sinusitis is frequently associated with the triad. YNS etiology remains unknown but a role of lymphatic impairment is usually evoked. YNS is more frequently isolated but may be associated in rare cases with autoimmune diseases, other clinical manifestations implicating lymphatic functions or cancer and, hence, is also considered a paraneoplastic syndrome. YNS management is symptomatic and not codified. YNS can resolve spontaneously. Oral vitamin E alone or even better when associated with triazole antifungals may achieve partial or total disappearance of nail discoloration. Pleural effusion can be treated surgically, with decortication/pleurectomy or pleurodesis. Antibiotic prophylaxis is prescribed for bronchiectasia with chronic sputum production. Lymphedema treatment is based on low-stretch bandages and the wearing of elastic compression garments combined with skin care, exercises and, as needed, manual lymph drainage.
\end{abstract}

Keywords: Yellow nail syndrome, Respiratory manifestations, Sinusitis, Lymphedema, Review

\section{Background}

The first case of yellow nail syndrome (YNS; OMIM 153300, ORPHA662) was probably reported by Heller in 1927 [1], but Samman \& White described the first series of patients who had yellow nails associated with lymphedema in 1964 [2]. That report included 13 patients (six men, seven women; age range at onset 25-65 years), all of whom had very slow measured nail growth associated with abnormal nail-plate discoloration, ranging from pale yellow to dark greenish, and frequent onycholysis. Eight of them had ankle edema; one patient each had facial edema or Milroy's disease (familial form of primary lymphedema). Four patients' limb lymphangiograms showed lymphatic abnormalities, such as tortuous, dilated or hypoplastic vessels, which the authors considered suggestive of lymphatic dysfunction or defective lymph drainage being responsible for YNS. In this review, we analyze the available literature on this subject, describing clinical characteristics, explorations, associated diseases and management of this rare syndrome.

\footnotetext{
* Correspondence: stephane.vignes@cognacq-jay.fr

'Department of Lymphology, Centre National de Référence des Maladies Vasculaires Rares (Lymphœedèmes primaires), Hôpital Cognacq-Jay, 15, rue Eugène-Millon, 75015 Paris, France

Full list of author information is available at the end of the article
}

\section{Methodology}

The literature search of the PubMed database used the words "yellow nail syndrome" for articles written in English or French. Other references cited in the identified articles were also considered.

\section{Definition}

YNS is characterized by a triad of thickened yellow nails, primary lymphedema and respiratory manifestations. It is an acquired condition of unknown etiology. It is a syndrome - not a disease - that is associated with conditions as different as diseases implicating the lymphatic system, autoimmune diseases or cancers. Whereas Samman \& White's first description of YNS included only nail discoloration, Emerson added pleural effusion to the diagnostic criteria [3]. Among the three clinical YNS characteristics (yellow nail syndrome, respiratory tract involvement, lymphedema), only two are required to diagnose YNS but it is difficult to call the entity YNS without nail abnormality [4]. Moreover, the three components are not necessarily present simultaneously, and may appear individually and sequentially, thereby making YNS diagnosis difficult. The complete triad is present only in $27-60 \%$ of the patients [5-10] (Table 1). The percentage differences of a given clinical 
Table 1 YNS clinical manifestations found in six large series of patients

\begin{tabular}{|c|c|c|c|c|c|c|}
\hline Manifestation & $\begin{array}{l}\text { Maldonado et al. } \\
{[6], N=41}\end{array}$ & $\begin{array}{l}\text { Hoque et al. [5], } \\
N=11\end{array}$ & $\begin{array}{l}\text { Piraccini et al. [7], } \\
N=21\end{array}$ & $\begin{array}{l}\text { Nordkild et al. [8], } \\
N=97\end{array}$ & $\begin{array}{l}\text { Varney et al. [9], } \\
N=17\end{array}$ & $\begin{array}{l}\text { Pavlidakey et al. [10], } \\
N=62\end{array}$ \\
\hline Yellow nails, $n(\%)$ & $41(100)$ & $10(91)$ & $21(100)$ & $86(89)$ & $17(100)$ & $53(85)$ \\
\hline $\begin{array}{l}\text { Chronic pulmonary } \\
\text { manifestations, } n(\%)\end{array}$ & $23(56)$ & $7(64)$ & $15(71)$ & $61(63)$ & $17(100)$ & 24 (39) (PEs only) \\
\hline Lymphedema, $n$ (\%) & $26(63)$ & $6(55)$ & $6(29)$ & $78(80)$ & $13(76)$ & $45(72)$ \\
\hline Sinusitis, $n(\%)$ & $17(41)$ & $3(27)$ & $3(14)$ & NR & $14(83)$ & $11(18)$ \\
\hline Complete triad & $\sim 60 \%$ & $27 \%$ & $29 \%$ & NR & $76 \%$ & $27 \%$ \\
\hline
\end{tabular}

$P E s$ pleural effusions, $N R$ not reported

manifestation may be attributed to the medical specialty that recruited the patients.

\section{Epidemiology}

No precise data are available to determine the exact prevalence of YNS, as fewer than 400 cases have been published in the literature, with an estimated prevalence $<1 / 1,000,000$. Cases have been described in all countries worldwide. YNS most often occurs in adults over 50 years old, with no sex predominance [5-7]. Pediatric forms are very rarely reported [11-21]: YNS may be present at birth (congenital) or develop before the age of 10 years [8].

A familial form of YNS has very rarely been described [5, 22-24], affecting two siblings $[25,26]$ or a family with eight cases in four sibships over two generations [22]. The very few reported familial cases mimic a dominant inheritance pattern, which is not supported by any genetic evidence [5]. YNS may be associated with intellectual disability, in which case it evokes a more complex syndrome [25] or occurs in cases of consanguinity [17].

\section{Diagnosis and diagnostic methods Yellow nails}

Yellow nails are the main clinical manifestation leading to YNS diagnosis. However, the possible interval between the first clinical sign (lymphedema, lung manifestations) and nail discoloration hinders affirmation of the YNS diagnosis. That yellowing represents a subset of chromonychia, defined as pathological nail discoloration, especially xanthonychia (yellow nail coloration). Nail discoloration varies from pale yellow to more or less dark greenish [27]. The nail plate becomes thickened, with an enhanced transverse curvature (overcurvature), sometimes with a notable hump, cross-ridging, very hard (scleronychia) and difficult-to-trim nail, and cuticle disappearance [28]. Usually opaque, the lunula disappears because of nail hyperkeratosis [27] (Fig. 1). Erythema may be seen in the proximal nail fold, frequently associated with chronic paronychia). Onycholysis (distal nail plate-nail bed separation) may occur with possible proximal spreading, leading to complete nail shedding [29, 30]. Longitudinal growth of the affected nail $(0.23 \mathrm{~mm}$ per week) was half that of a normal nail $(0.46 \mathrm{~mm}$ per week) $[2,31]$. The affected nail's thickness $(0.97 \mathrm{~mm})$ was double that of a normal nail $(0.57 \mathrm{~mm})$, suggesting that the nail that grows half as fast and twice as thick [31].

\section{Pulmonary manifestations}

Lung involvement in YNS, which occurred in $56-71 \%$ of the patients, diversely affected some parts of the respiratory tract with a variety of clinical manifestations [6-8]. Chronic cough is the most frequent pulmonary manifestation seen in $56 \%$ of YNS patients [6], with pleural effusions found in $14-46 \%$ of the patients [6, 7].

Based on their retrospective systematic review of more than 150 patients described in publications identified with the search terms "pleural effusion" and "YNS",

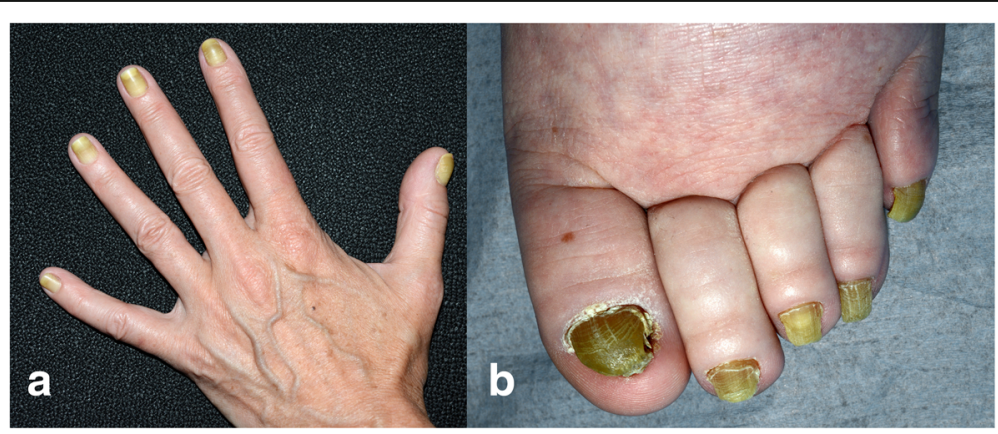

Fig. 1 Yellowing of all 10 (a) finger and (b) toe nails 
Valdés et al. recently reported the characteristics of these pleural effusions [32]: $68.3 \%$ were bilateral; the fluid appeared serous in 75\%, milky (chylothorax) in $22 \%$ and purulent (empyemas) in 3.5\%; 95\% of effusions were described as exudates (median protein level: $4.2 \mathrm{~g} / \mathrm{dl}$ ) and $5 \%$ as transudates that harbored a median nucleated cell count of 1540 cells $/ \mathrm{mm}^{3}$ with $96 \%$ lymphocytic predominance.

However, sputum bacteria (Pseudomonas aeruginosa, Haemophilus influenzae, Streptococcus pneumoniae, Moraxella catarrhalis) are the same in idiopathic and YNS-associated bronchiectasias [33]. Recurrent pneumonias occur in $22 \%$ of the patients. Also, bilateral apical fibrosis, patchy alveolar infiltrates and cystic lesions are very rarely observed in YNS patients [33, 34].

YNS patients' pulmonary function test results are usually normal or may indicate a moderate-to-severe restrictive syndrome attributable to pleural effusions [4]. Extremely rare patients may have mixed obstructive-restrictive syndrome or decreased diffusion capacity [6]. Histological examination of pleural biopsies revealed normal morphology or that of chronic fibrosing pleuritis, and did not provide any further information; biopsies are usually not contributive [32]. Bronchiectasias are present in $44 \%$. Chest computed-tomography (CT) scan is the best imaging technique to diagnose bronchiectasia, which, in YNS patients, is significantly less extensive, severe and with lower bronchial wall thickness scores than in matched idiopathic bronchiectasia patients [33].

\section{Lymphedema}

Lymphedema is a clinical feature of YNS, occurring in $29-80 \%$ of the reported series, and may be the first sign of the disease in about one-third of them [6-8]. Lymphedema characteristics do not differ from those of primary lymphedema. It involves the lower limbs, especially bilateral and below the knee (Fig. 2). The increased volume of the lymphedematous limb is caused by excess lymph accumulation but also fibrosis resulting from fibroblast stimulation and excess adipose tissue due to adipocyte stimulation $[35,36]$. Stemmer's sign (inability to pinch the skin on the dorsal side or the base of the second toe) is pathognomonic of lymphedema and is fibrosis-related. Superficial edema is responsible for the more-or-less present pitting edema. Lymphedema is a chronic disease, with a major tissular component leading to incomplete reversibility under treatment. Although cellulitis (erysipelas) is the main lymphedema complication, discomfort, esthetic prejudice and diminished quality of life also complicate the disease [37, 38].

\section{Sinusitis}

Acute or chronic rhinosinusitis is very common in YNS patients, estimated between 14 and 83\% [5-10].

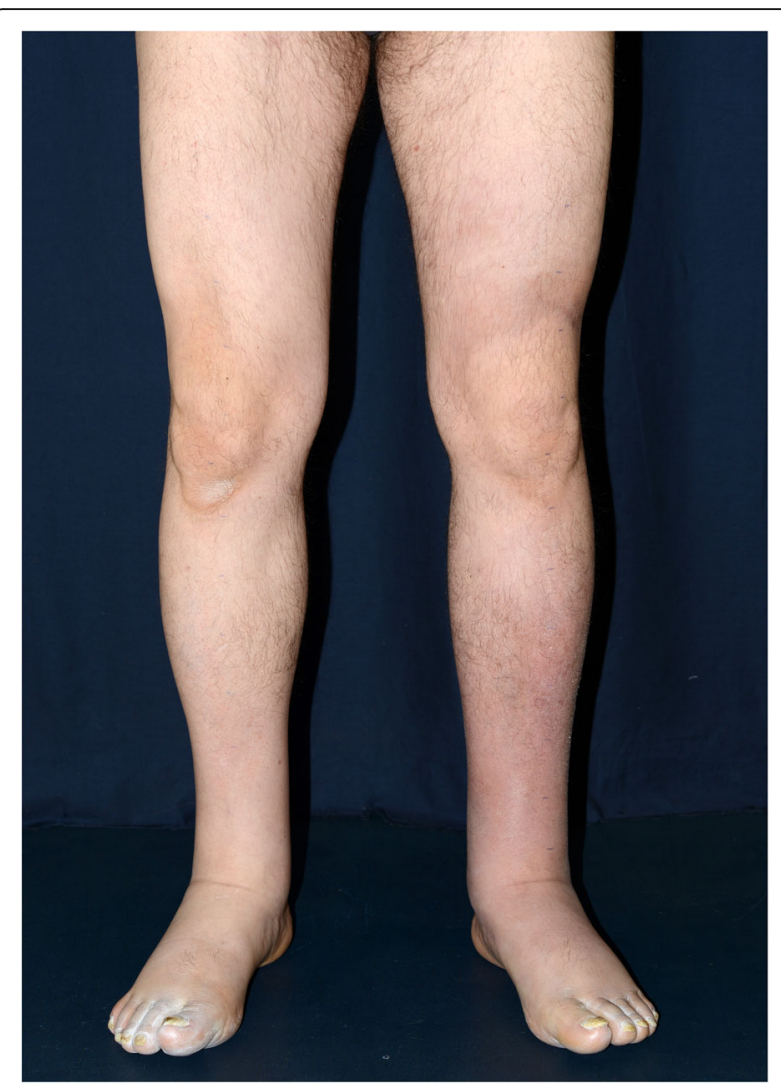

Fig. 2 Bilateral lower limb lymphedema involving the feet, ankles and calves, with accentuation of the flexion folds

The maxillary sinus is the most frequently affected, followed by ethmoid, frontal and sphenoid [9] (Fig. 3). Nasal symptom onset may precede nail changes by a few years, appear simultaneously or arise subsequently. Clinical signs include daily mucopurulent rhinorrhea, nasal obstruction and frequent post-nasal drip. Nasal airway examination usually finds narrowed nasal pathways, mucosal inflammation with variable enlargement of the turbinates and the presence of mucopus. Other symptoms may be associated, e.g., headaches or recurrent facial pain. Non-contrast sinus CT scans show mucosal thickening, with fluid levels sometimes reported.

\section{Other manifestations}

Very rare ocular involvement has been reported: chemosis, corneal micropannus (vascularized sheet of fibrous tissue overlying the cornea), eyelid lymphedema, thickened conjunctiva [39, 40]. Anecdotal associations have also been described: anhydrosis, pectus excavatum, eosinophilia-myalgia syndrome, bullous stomatitis, sarcoidosis and Raynaud's phenomenon, cerebral aneurysm and pancytopenia [6]. 


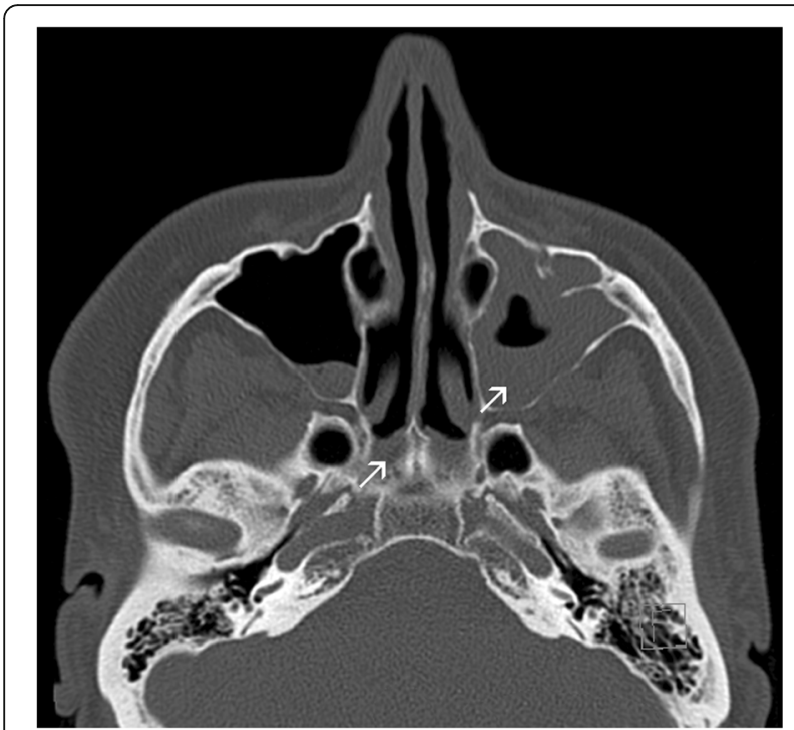

Fig. 3 Sinus computed-tomography scan: note the subtotal opacity of the left maxillary sinus and ethmoidal sinusitis

\section{Children}

Among children with YNS, 75\% had lung manifestations (infections, pleural effusions, bronchial dilations and/or bronchial cysts) and ear-nose-throat symptoms in 31\%, with a moderate female predominance [20]. Lymphedema prevalence ranged from 56 to $80 \%$ of YNS children and may appear later than the nail discoloration [8].

\section{Pathogenesis}

Although YNS etiology of remains unknown, some hypotheses were advanced. Lymphatic involvement is often evoked to explain lymphedema, pleural effusion (particularly chylothorax) or nail discoloration but it is difficult to implicate it in bronchiectasia and sinusitis. Lymphatic impairment is not easy to confirm. Four YNS patients underwent lower limb direct lymphangiography, less used at present, but lymphatic abnormalities were noted only in the patient with severe lymphedema. Quantitative limb lymphoscintigraphy with ${ }^{99 m}$ Tc-colloidal antimony sulfide revealed less activity (percentage uptake) in the draining lymph nodes (inguinofemoral or axillary) [41]. Moreover, the uptake percentages in the axillary/inguinal lymph nodes of the YNS group were significantly lower than those of the normal controls but significantly higher than those of subjects with primary or secondary lymphedema, hence more suggestive of impaired lymph transport than the lymphatic hypoplasia/aplasia seen in true primary lymphedema. Furthermore, the YNS group without lower limb edema had better lymphatic drainage than those with edema [42] (Fig. 4). Maldonado et al. thought that YNS pathophysiology might be attributable to microvasculopathy associated with protein leakage rather than functional lymphatic impairment [43]. Notably,

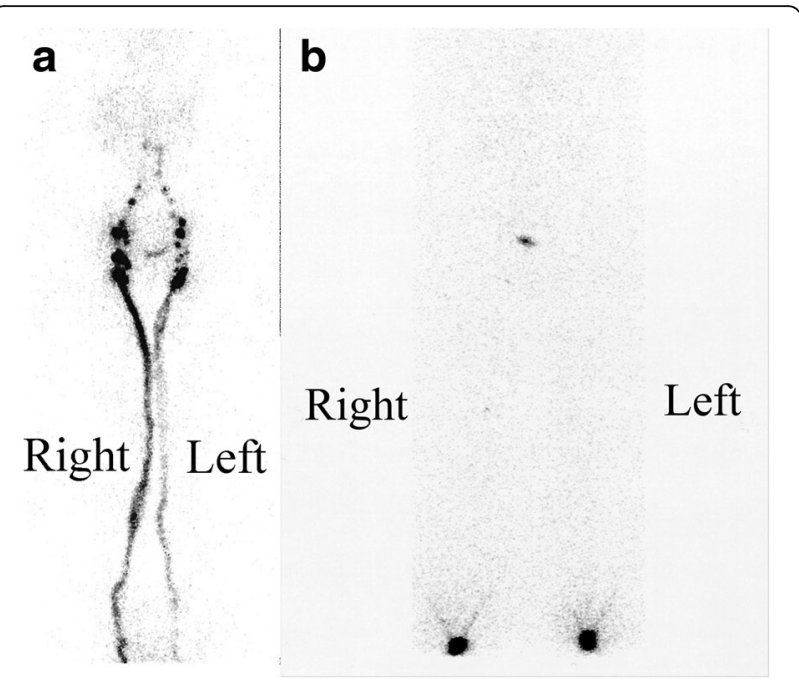

Fig. 4 Lower-limb lymphoscintigraphy images were obtained 40 min after injecting ${ }^{99 m}$ technetium-labeled colloidal albumin into two patients with the complete YNS triad: moderate lymphostasis and slightly decreased (a) or absent (b) inguinal lymph-node uptake

nailfold capillaroscopy occasionally showed dilated and tortuous capillary loops [44].

Defective lymphatic drainage might be responsible for the slow growth and thickened nails observed in YNS, and may reflect subungual tissue sclerosis leading to lymphatic obstruction. Light microscopy examination of sections of nail-matrix tissue revealed replacement of the normally loose fibrovascular subungual stroma by dense, fibrous tissue (composed of dense collagen deposits) extending from the immediate subepithelial stroma to a depth of $2.5 \mathrm{~mm}$. Numerous ectatic, endothelium-lined channels were prominent within the fibrotic stroma [45]. Fibrosis and dilated lymphatic vessels were also seen in the parietal pleura of a YNS patient $[46,47]$. The accumulation of lipofuscin pigment was advanced to explain the yellow discoloration [48], whereas abnormal nail keratinization might be explained by the presence electron microscopy-visualized keratohyalin granules, not found in normal adult nails.

More recently, it was hypothesized that titanium, especially titanium dioxide, might play a role in YNS. High titanium levels (determined by energy dispersive $\mathrm{X}$-ray fluorescence) were detected in the nails of YNS patients but not in control nails. The authors postulated that titanium ions were released from titanium implants (inlays, crown) in the teeth or jaws through the galvanic action of amalgam or localized oxidative action of fluorides [49-51]. Other sources of titanium ions were also suggested: joint implants, surgical staples, foods (chewing gum to try to explain YNS in children), medication excipients, cosmetics (sunscreen, moisturizers, shampoo, toothpaste) $[50,52]$. Titanium's 
hypothetical role remains possible, but probably not sufficient, because its presence in other organs (liver, spleen, lymph nodes, lung) of autopsied patients was not accompanied with nail yellowing [53].

\section{Associated diseases}

Several infants had YNS associated with non-immune hydrops fetalis; this association is probably not fortuitous [54]. Non-immune hydrops fetalis was present at birth $[20,55]$. A child with YNS had a brother who died of non-immune hydrops fetalis, suggesting a possible relationship between the two diseases [17].

YNS is very rarely associated with primary intestinal lymphangiectasia (Waldmann's disease) (OMIM 152800, ORPHA90362) or lymphedema-distichiasis syndrome (OMIM 153400, ORPHA33001), suggesting that these entities have overlapping characteristics, including lymphatic impairment [56, 57]. Waldmann's disease is characterized by primary intestinal lymphangiectasia, with lymph leakage into the bowel lumen leading to hypoalbuminemia, hypogammaglobulinemia and lymphopenia [58]. Distichiasis is defined as double or more rows of eyelashes localized on the Meibomian gland orifices [59].

The YNS association with malignant disease raises the hypothesis that it might be a paraneoplastic syndrome but that notion remains controversial. The frequency of cancer being diagnosed concurrently or closely thereafter in YNS patients was estimated at 4/41 [6] and 1/21 [7]. Various types of cancers were associated with YNS: bronchial carcinoma [60,61], breast $[7,62,63]$, nonHodgkin lymphoma [64, 65], gallbladder [6, 66], larynx [67], renal cell carcinoma [6], endometrium [68], melanoma [3], multiple myeloma after hematopoietic stem-cell transplantation [69] or precancerous mycosis fungoides [28]. The YNS-to-cancer-diagnosis interval ranges from days to years, with gradual development of the complete YNS triad [61].

YNS was occasionally associated with autoimmune diseases [70], immunodeficiency disorders, such as common variable immunodeficiency, combined T- and B-cell deficiency [70, 71], Guillain-Barré syndrome [72], nephrotic syndrome [73, 74], Hashimoto's thyroiditis, severe hypothyroidism or hyperthyroidism [75-77], xanthogranulomatous pyelonephritis [78] and rheumatoid arthritis even without thiol-analog use [79].

Immunological studies on YNS patients are very scarce. Isolated case reports associated YNS with IgA deficiency [22] or hypogammaglobulinemia [80]. Bokszczanin \& Levinson described a 57-year-old woman with YNS and poor selective responses after vaccination against Streptococcus pneumoniae and Haemophilus influenzae [81], which might explain, in part, the recurrent lung or sinus infections in YNS. Gupta et al. reported lymphopenia in two YNS patients (one with common variable immunodeficiency) with low percentages of $\mathrm{CD} 4^{+} \mathrm{T}$ cells, high percentages of $\mathrm{CD} 8^{+} \mathrm{T}$ cells and severe naïve $\mathrm{CD} 4^{+}$and $\mathrm{CD} 8^{+} \mathrm{T}$-cell deficits responsible for muted T-cell responses to antigens. A suggested mechanism for diminished naïve T-cell subsets might be less thymus output (thymus involution and/or apoptosis) [70]. It is of interest to note that, in another rare disease with lymphatic abnormality, primary intestinal lymphangiectasia (Waldmann's disease), immunological investigation results were similar to those of YNS patients [82].

\section{Differential diagnosis of nail discoloration \\ Drugs}

D-Penicillamine, bucillamine and tiopronin are three thiol compounds used for long-term treatment of rheumatoid arthritis. For the rare cases of drug-related YNS, nail discoloration was the first manifestation in $88 \%$ of them, but it was less frequently associated with pleural effusion and lymphedema than in YNS not drugrelated [83, 84]. Competitive inhibition of disulfidebinding in keratin biosynthesis is postulated to explain the major slowing of nail plate growth in bucillaminetreated patients. Moreover, thiol drugs contain cysteine, which is also a major nail component. After bucillamine withdrawal, nail discoloration declined in over $90 \%$ of the affected patients but lymphedema and pulmonary manifestations were attenuated in only 30-35\% [84]. Gold and methotrexate, also used to treat rheumatoid arthritis, are less suspected of being associated with YNS [85].

\section{Infections}

Nail yellowing is abnormal and may be attributable to something other than YNS. Nail infection or mycosis should be ruled out before considering YNS. Candida-, Aspergillus- or dermatophyte-caused nail mycosis may cause such discoloration. Pseudomonas aeruginosa, via production of the blue-green pigments pyoverdin and pyocyanin, may be responsible for chloronychia (green rather than yellow nail discoloration) in the elderly [86]. Chloronychia is more common in homemakers, barbers, dishwashers, bakers and medical personnel.

\section{Others}

In children and adults, differential diagnoses include planus lichen, psoriasis or alopecia areata, chronic paronychia, onychogryphosis and acquired pachyonychia [87-89]. Yellow nail discoloration may also have rare local and toxic causes (Table 2) [90].

\section{Treatment}

YNS treatment is not codified. YNS may resolve in few months without treatment [91] or, when it is a paraneoplastic syndrome, after cancer therapy [62]. 
Table 2 Rare, usually work-related, local toxic causes of yellow nail discoloration, from [90]

Epoxy systems: metaphenylenediamine, 4,4'-methylenedianiline

Flower handling

Pesticides: diquat, paraquat, dinitroorthocresol, dinobuton

Chromium salts

Dyestuffs: dinitrosalicylic acid, dinitrobenzene, dinitrotoluene, trinitrotoluene

\section{Yellow nail changes}

The main aim is to improve the frequently unesthetic nail appearance and associated pain, due, in part, to onycholysis. A few drugs have been proposed to treat the nail discoloration with inconsistent efficacy. None of the following treatments can be recommended systematically to treat YNS.

\section{Systemic treatments of yellow nails}

Oral vitamin $\mathrm{E}$ is the only agent that successfully treated YNS [48, 92-95]. Oral $\alpha$-tocopherol (vitamin E) was frequently prescribed at 1000-1200 IU/day, with incomplete or inconstant efficacy. Norton's hypothesized, as follows, that vitamin E would be effective: lipofuscin pigments, possibly responsible for nail yellowing, are derived from colorless lipid precursors, transformed by oxidation in tissue to produce varying degrees of yellow; vitamin $\mathrm{E}$ has proven in vitro antioxidant properties, and in vivo might protect cell membranes against free-radical-mediated oxidative damage, thereby potentially blocking lipofuscin-pigment production [48].

Although YNS is not caused by fungal infection, triazole antifungals were regularly used to treat it. Itraconazole, given at $400 \mathrm{mg} /$ day for 1 week/month for 6 months, achieved only two mild attenuations and two cures among eight patients (one relapsed after drug discontinuation) [96]. Among the 13 patients who took oral fluconazole (300 mg once weekly) and oral $\alpha$-tocopherol (1000 IU/day), two benefited from clinical improvement and 11 were considered clinical cures [97], without any efficacy on other YNS manifestations. One of the hypotheses to explain that partial efficacy is based on azole antifungal stimulation of linear nail growth [98, 99].

Oral zinc sulfate supplementation (300 mg daily) obtained attenuation of nail yellowing or growth and lymphedema after 8 months of treatment but no modification of pulmonary manifestations [95].

Clarithromycin (400 mg/day, 6 years) successfully treated one patient [100].

A patient with common variable immunodeficiency treated with subcutaneous immunoglobulin mounted good responses in terms of frequency of infections, lymphedema and pleural effusions [70].

\section{Local treatments}

Intralesional steroids, such as topical triamcinolone acetonide $(5 \mathrm{mg} / \mathrm{ml} /$ injection, $0.1-0.2 \mathrm{ml}$ for each affected nail), were proposed alone or combined with fluconazole and vitamin $\mathrm{E}[92,101]$.

In a first study published in 1991, Williams et al. prescribed topical vitamin $\mathrm{E}$; the treated nails improved clinically and growth rates rose [94]. In a randomized study using a vitamin $\mathrm{E}$ preparation (solution of 20,000 IU of tocopherol acetate/fluid ounce of safflower oil) applied twice daily to the nails), no difference (appearance or nail growth) versus placebo was observed after 6 months of administration [23].

\section{Pulmonary manifestations}

Symptomatic treatments are prescribed. Patients may receive antibiotics for acute exacerbation of bronchiectasia, whereas, for patients with poor symptom control and/or recurrent exacerbations, low-dose antibiotic prophylaxis, such as oral azithromycin (usually $250 \mathrm{mg} 3$ times/week), achieved attenuation of chest symptoms for the majority of them [33]. Physiotherapy training (postural drainage, chest physiotherapy, flutter valve), combined or not with antibiotic prophylaxis, is also prescribed to help patients self-manage their chronic expectoration.

Vaccinations against flu and pneumococci are strongly recommended. Surgical intervention of recurrent and/or large pleural effusions is useful: decortication/pleurectomy, pleurodesis (talc [47, 102], picibanil [103], quinacrine [4]) and pleural-peritoneal shunts were the most effective treatments of symptomatic pleural effusions with, respectively, 89,82 and $67 \%$ partial or complete responses [33].

Octreotide, a somatostatin analog, was also used to treat YNS pleural effusions or chylous ascites and lymphedema, and generated positive responses [47, 104-107]. Somatostatin analogues reduce intestinal lipid absorption and lower the triglyceride concentration in the thoracic duct in animals [108]. Those actions could explain the diminution of the chylous but not non-chylous effusions present in most YNS patients. Octreotide was initially administered subcutaneously ( $0.5 \mathrm{mg}$ twice daily) to ensure safety, followed by the long-acting repeatable formulation $(30 \mathrm{mg}$ given once/month) with or without progressive dose diminution $[105,107]$. One initial octreotide responder became "resistant", suggesting tachyphylaxis to long-lasting treatment, as previously described for acromegaly patients receiving chronic treatment. Lanreotide, an alternative somatostatin analog, may be useful for such cases $[47,109]$.

\section{Lymphedema}

Complete decongestive therapy, also called complex or multimodal decongestive physiotherapy, is the term proposed by Michael Földi in the 1980s to define 
lymphedema treatment. This approach is divided into two separate phases [110]. The first, intended to obtain the most important lymphedema-volume reduction, is comprised of several components: low-stretch bandage, manual lymph drainage, skin/nail care (to detect and eliminate potential sites of entry for infection) and exercises, each having its own specific objective and role in limiting the impact of this disorder. The intensive strategy of this stage aims to achieve 30-40\% lymphedema-volume reduction [111], eliminating only the fluid component of lymphedema. The second phase of complete decongestive therapy helps stabilize lymphedema volume over the long-term and is based on wearing a high-pressure elastic garment, exercises, skin care and, sometimes, manual lymph drainage [112]. Each patient should be offered several training sessions in validated specific patient-education programs to master the wrapping procedure and verify good understanding and implementation. Overnight bandaging at least three times per week is recommended during long-term maintenance. The aim of learning selfbandaging is to improve the patient's autonomy to manage his/her own lymphedema [113].

\section{Sinusitis}

Treatment of acute sinusitis is based on antibiotics (amoxicillin-clavulanate (1.5-3 g/day), or, in the case of penicillin allergy, doxycycline $(200 \mathrm{mg} /$ day $)$, fluoroquinolone (levofloxacin, $500 \mathrm{mg} /$ day) or moxifloxacin $(400 \mathrm{mg} /$ day)) for 5-7 days [114]. Treatment of chronic sinusitis is not specific for YNS patients but global responses to medications, including short-course oral antibiotics, topical intranasal steroids, saline irrigation and topical or oral decongestant, are poor [115]. Surgical procedures may be necessary and are essentially based on endoscopic sinus surgery (endoscopic middle meatal antrostomy, conventional inferior meatal antrostomy) [116].

\section{Prognosis}

Spontaneous remission of the nail changes has been observed in up to $30 \%$ of the YNS patients, regardless of treatment [5]. Remission of nail changes was more likely for fingernails than toenails, perhaps because of persistent lower limb lymphedema, which might maintain the presumed lymphatic pathophysiology [5]. More generally, the attenuated discoloration is not associated with simultaneous regression of other systemic manifestations. In YNS associated with malignant disease, treatment of the latter may lead to attenuation or disappearance of the clinical YNS signs $[62,69]$. In Maldonado et al.'s study, 17 of the 37 patients with available follow-up information died after a median of 82 months [6]. In that study, a Kaplan-Meier survival curve estimated median survival at 132 months, shorter than that of a paired-control population.

\section{Conclusion}

YNS is very rare disorder associating yellow nail discoloration, lung manifestations/sinusitis and lymphedema. It is more frequently isolated but may be associated with other diseases implicating the lymphatic system, autoimmune diseases or cancers. Its etiology remains unknown, although lymphatic impairment is regularly evoked in the literature. Titanium is a more recent hypothetical agent but so far remains unconfirmed to explain the syndrome. YNS treatment is symptomatic for each component: yellow nails, pulmonary manifestations/sinusitis, lymphedema. Vitamin E combined with fluconazole, usually prescribed to treat yellow nails, achieves partial or complete responses. Spontaneous resolution is also possible. Research is required to better understand and treat this rare and very poorly recognized disease.

Abbreviations

YNS: Yellow nail syndrome

Acknowledgments

Not applicable.

Funding

Not applicable.

Availability of data and materials

Data sharing not applicable to this article as no datasets were generated or analyzed during the current study.

Authors' contributions

SV conceived, designed and wrote the review, RB wrote the review. Both authors read and approved the final manuscript.

Competing interests

The authors declare that they have no competing interests.

Consent for publication

Not applicable.

Ethics approval and consent to participate Not applicable.

\section{Author details}

'Department of Lymphology, Centre National de Référence des Maladies Vasculaires Rares (Lymphœdèmes primaires), Hôpital Cognacq-Jay, 15, rue Eugène-Millon, 75015 Paris, France. ${ }^{2}$ Nail Disease Centre, 42, rue des Serbes, 06400 Cannes, France.

Received: 26 October 2016 Accepted: 21 February 2017

Published online: 27 February 2017

\section{References}

1. Heller J. Die Krankheiten der Nagel. In: Jadassohn's Handbuch der Haut und Geschlechtskrankheiten, vol. 13 part 2. Berlin: Julius Springer; 1927. p. 423.

2. Samman PD, White WF. The yellow nail syndrome. Br J Dermatol. 1964;76: 153-7. doi:10.1111/j.1365-2133.1964.tb14499.x.

3. Emerson PA. Yellow nails, lymphoedema, and pleural effusions. Thorax. 1966;21:247-53.

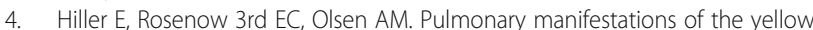
nail syndrome. Chest. 1972;61:452-8. doi:10.1378/chest.61.5.452. 
5. Hoque SR, Mansour S, Mortimer PS. Yellow nail syndrome: not a genetic disorder? Eleven new cases and a review of the literature. Br J Dermatol. 2007;156:1230-4. doi:10.1111/j.1365-2133.2007.07894.x.

6. Maldonado F, Tazelaar HD, Wang CW, Ryu JH. Yellow nail syndrome: analysis of 41 consecutive patients. Chest. 2008;134:375-81. doi:10.1378/chest.08-0137.

7. Piraccini BM, Urciuoli B, Starace $M$, Tosti A, Balestri R. Yellow nail syndrome: clinical experience in a series of 21 patients. J Dtsch Dermatol Ges. 2014;12: 131-7. doi:10.1111/ddg.12216.

8. Nordkild P, Kromann-Andersen H, Struve-Christensen E. Yellow nail syndrome - the triad of yellow nails, lymphoedema, and pleural effusions. A review of the literature and a case report. Acta Med Scand. 1986;219:221-7.

9. Varney VA, Cumberworth V, Sudderick R, Durham SR, Mackay IS. Rhinitis, sinusitis and the yellow nail syndrome: a review of symptoms and response to treatment in 17 patients. Clin Otolaryngol Allied Sci. 1994;19:237-40. doi: 10.1111/j.1365-2273.1994.tb01222.x.

10. Pavlidakey GP, Hashimoto K, Blum D. Yellow nail syndrome. J Am Acad Dermatol. 1984;11:509-12. doi:10.1016/S0190-9622(84)70201-5.

11. Magid M, Esterly NB, Prendiville J, Fujisaki C. The yellow nail syndrome in an 8year-old girl. Pediatr Dermatol. 1987;4:90-3. doi:10.1111/j.1525-1470.1987.tb00758x

12. Paradisis $M$, Van Asperen P. Yellow nail syndrome in infancy. J Paediatr Child Health. 1997;33:454-7. doi:10.1111/j.1440-1754.1997.tb01642.x.

13. Göçmen A, Küçükosmanoglu O, Kiper N, Karaduman A, Ozçelik U. Yellow nail syndrome in 10-year-old girl. Turk J Pediatr. 1997:39:105-9.

14. Yalçin E, Dogru D, Gönç EN, Cetinkaya A, Kiper N. Yellow nail syndrome in an infant presenting with lymphedema of the eyelids and pleural effusion. Clin Pediatr (Phila). 2004;43:569-72.

15. Douri T. Yellow nail syndrome in two siblings. Dermatol Online J. 2008;14:7.

16. Cebeci F, Celebi M, Onsun N. Non classical yellow nail syndrome in 6-yearold girl: a case report. Cases J. 2009;2:165. doi:10.1186/1757-1626-2-165.

17. Nanda A, Al-Essa FH, El-Shafei WM, Alsaleh QA. Congenital yellow nail syndrome: a case report and its relationship to nonimmune fetal hydrops. Pediatr Dermatol. 2010;27:533-4. doi:10.1111/j.1525-1470.2010.01259.x.

18. Siddiq I, Hughes DM. Yellow nails, lymphedema and chronic cough: yellow nail syndrome in an eight-year-old girl. Can Respir J. 2012;19:35-6.

19. Cecchini M, Doumit J, Kanigsberg N. Atypical presentation of congenital yellow nail syndrome in a 2-year-old female. J Cutan Med Surg. 2013;17:66-8.

20. Dessart P, Deries X, Guérin-Moreau M, Troussier F, Martin L. Syndrome des ongles jaunes: deux cas pédiatriques. Ann Dermatol Venereol. 2014;141: 611-9. doi:10.1016/j.annder.2014.06.026.

21. Al Hawsawi K, Pope E. Yellow nail syndrome. Pediatr Dermatol. 2010;27:6756. doi:10.1111/j.1525-1470.2010.01338.x.

22. Wells GC. Yellow nail syndrome with familial primary hypoplasia of lymphatics, manifest late in life. Proc Royal Soc Med. 1966;59:447.

23. Lambert EM, Dziura J, Kauls L, Mercurio M, Antaya RJ. Yellow nail syndrome in three siblings: a randomized double-blind trial of topical vitamin $\mathrm{E}$. Pediatr Dermatol. 2006;23:390-5. doi:10.1111/j.1525-1470.2006.00251.

24. Razi E. Familial yellow nail syndrome. Dermatol Online J. 2006;12:15.

25. Kamatani M, Rai A, Hen H, Hayashi K, Aoki T, Umeyama K, et al. Yellow nail syndrome associated with mental retardation in two siblings. $\mathrm{Br} J$ Dermatol. 1978;99:329-33. doi:10.1111/j.1365-2133.1978.tb02005.x.

26. Kleinman PK. Congenital lymphedema and yellow nails. J Pediatr. 1973;83: 454-6.

27. Baran R. Pigmentations of the nails (chromonychia). J Dermatol Surg Oncol. 1978:4:250-4.

28. Stosiek N, Peters KP, Hiller D, Riedl B, Hornstein OP. Yellow nail syndrome in a patient with mycosis fungoides. J Am Acad Dermatol. 1993;28:792-4. doi: 10.1016/S0190-9622(09)80277-6.

29. Holzberg M. The nail in systemic disease. In: Baran R, de Berker DAR, Holzberg M, Thomas L, editors. Baran and Dawber's diseases of the nails and their management. 4th ed. Oxford: Wiley-Blackwell; 2012. p. 328-30.

30. Venencie PY, Dicken $\mathrm{CH}$. Yellow nail syndrome: report of five cases. J Am Acad Dermatol. 1984;10:187-92. doi:10.1016/S0190-9622(84)70021-1.

31. Moffitt DL, de Berker DA. Yellow nail syndrome: the nail that grows half as fast grows twice as thick. Clin Exp Dermatol. 2000;25:21-3. doi:10.1046/j. 1365-2230.2000.00563.x.

32. Valdés L, Huggins JT, Gude F, Ferreiro L, Alvarez-Dobaño JM, Golpe A, et al. Characteristics of patients with yellow nail syndrome and pleural effusion. Respirology. 2014;19:985-92. doi:10.1111/resp.12357.

33. Woodfield G, Nisbet M, Jacob J, Mok W, Loebinger MR, Hansell DM, et al. Bronchiectasis in yellow nail syndrome. Respirology. 2017;22:101-7. doi:10.1111/resp.12866.
34. Sacco O, Fregonese B, Marino CE, Mattioli G, Gambini C, Rossi GA. Yellow nail syndrome and bilateral cystic lung disease. Pediatr Pulmonol. 1998;26:29-33.

35. Szuba A, Rockson SG. Lymphedema: classification, diagnosis and therapy. Vasc Med. 1998:3:145-56.

36. Zampell JC, Aschen S, Weitman ES, Yan A, Elhadad S, De Brot M, et al. Regulation of adipogenesis by lymphatic fluid stasis: part I. Adipogenesis, fibrosis, and inflammation. Plast Reconstr Surg. 2012;129:825-34. doi:10.1097/PRS.0b013e3182450b2d.

37. Dupuy A, Benchikhi H, Roujeau JC, Bernard P, Vaillant L, Chosidow O, et al. Risk factors for erysipelas of the leg (cellulitis): case-control study. BMJ. 1999:318:1591-4.

38. Okajima S, Hirota A, Kimura E, Inagaki M, Tamai N, et al. Health-related quality of life and associated factors in patients with primary lymphedema. Jpn J Nurs Sci. 2013;10:202-11. doi:10.1111/j.1742-7924.2012.00220.x.

39. Maisels DO, Korachi AO. Lymphoedema of the eyelids in the yellow nail syndrome. Br J Plast Surg. 1985;38:93-6.

40. Bourcier T, Baudrimont M, Borderie V, Mayaud C, Laroche L. Conjunctival changes associated with yellow nail syndrome. Br J Ophthalmol. 2002:86:930.

41. Marks R, Ellis JP. Yellow nails: a report of six cases. Arch Dermatol. 1970;102: 619-23. doi:10.1001/archderm.1970.04000120037006.

42. Bull RH, Fenton DA, Mortimer PS. Lymphatic function in the yellow nail syndrome. Br J Dermatol. 1996;134:307-12. doi:10.1111/j.1365-2133.1996. tb07619.x.

43. Maldonado F, Ryu JH. Yellow nail syndrome. Curr Opin Pulm Med. 2009;15: 371-5. doi:10.1097/MCP.0b013e32832ad45a.

44. D'Alessandro A, Muzi G, Monaco A, Filiberto S, Barboni A, Abbritti G. Yellow nail syndrome: does protein leakage play a role? Eur Respir J. 2001;17:149-52.

45. DeCoste SD, Imber MJ, Baden HP. Yellow nail syndrome. J Am Acad Dermatol. 1990;22:608-11. doi:10.1016/0190-9622(90)70081-R.

46. Solal-Céligny $P$, Cormier Y, Fournier M. The yellow nail syndrome. Light and electron microscopic aspects of the pleura. Arch Pathol Lab Med. 1983;107:183-5.

47. Brooks KG, Echevarria C, Cooper D, Bourke SC. Case-based discussion from North Tyneside General Hospital: somatostatin analogues in yellow nail syndrome associated with recurrent pleural effusions. Thorax. 2014:69:967-8. doi:10.1136/thoraxjnl-2014-205426.

48. Norton L. Further observations on the yellow nail syndrome with therapeutic effects of oral alpha-tocopherol. Cutis. 1985;36:457-62.

49. Berglund F, Carlmark B. Titanium, sinusitis, and the yellow nail syndrome. Biol Trace Elem Res. 2011;143:1-7. doi:10.1007/s12011-010-8828-5.

50. Decker A, Daly D, Scher RK. Role of titanium in the development of yellow nail syndrome. Skin Appendage Disord. 2015;1:28-30. doi:10.1159/ 000375171.

51. Ataya A, Kline KP, Cope J, Alnuaimat H. Titanium exposure and yellow nail syndrome. Respir Med Case Rep. 2015;16:146-7. doi:10.1016/j.rmcr.2015.10.002.

52. Hsu TY, Lin CC, Lee MD, Chang BP, Tsai JD. Titanium dioxide in toothpaste causing yellow nail syndrome. Pediatrics. 2017;139:e20160546. doi:10.1542/ peds.2016-0546.

53. Dos Santos VM. Titanium pigment and yellow nail syndrome. Skin Appendage Disord. 2016:1:197. doi:10.1159/000445722.

54. Slee J, Nelson J, Dickinson J, Kendall P, Halbert A. Yellow nail syndrome presenting as non immune hydrops: second case report. Am J Med Genet. 2000;93:1-4.

55. Govaert P, Leroy JG, Pauwels R, Vanhaesebrouck P, De Praeter C, Van Kets $H$ et al. Perinatal manifestations of maternal yellow nail syndrome. Pediatrics. 1992;89:1016-8

56. Desramé J, Béchade D, Patte JH, Jean R, Karsenti D, Coutant G, et al. Syndrome des ongles jaunes associé à des lymphangiectasies intestinales. Gastroenterol Clin Biol. 2000;24:837-40. doi: GCB-08-2000-24-8-0399-8320101019-ART16.

57. Duhra PM, Quigley EM, Marsh MN. Chylous ascites, intestinal lymphangiectasia and the 'yellow-nail' syndrome. Gut. 1985;26:1266-9.

58. Vignes S, Bellanger J. Primary intestinal lymphangiectasia (Waldmann's disease). Orphanet J Rare Dis. 2008:3:5. doi:10.1186/1750-1172-3-5.

59. Brice G, Mansour S, Bell R, Collin JR, Child AH, Brady AF, et al. Analysis of the phenotypic abnormalities in lymphoedema-distichiasis syndrome in 74 patients with FOXC2 mutations or linkage to 16q24. J Med Genet. 2002;39: 478-83. doi:10.1136/jmg.39.7.478.

60. Thomas PS, Sidhu B. Yellow nail syndrome and bronchial carcinoma. Chest. 1987:92:191. doi:10.1378/chest.92.1.191a.

61. Carnassale G, Margaritora S, Vita ML, Mariantonia A, Congedo MT, Cusumano G, et al. Lung cancer in association with yellow nail syndrome. J Clin Oncol. 2011;29:e156-8. doi:10.1200/JCO.2010.31.8402. 
62. lqbal M, Rossoff $\amalg$, Marzouk KA, Steinberg HN. Yellow nail syndrome: resolution of yellow nails after successful treatment of breast cancer. Chest. 2000;117:1516-8. doi:10.1378/chest.117.5.1516.

63. Gupta AK, Davies GM, Haberman HF. Yellow nail syndrome. Cutis. 1986;37: 371-4.

64. Ginarte M, Monteagudo B, Toribio J. Yellow nail syndrome and lung lymphoma Clin Exp Dermatol. 2004;29:432-4. doi:10.1111/j.1365-2230.2004.01541.x.

65. Sève $P$, Thieblemont $C$, Dumontet $C$, Bouafia F, Arnaud $P$, Hequet $O$, et al. Skin lesions in malignancy. Case 3. Yellow nail syndrome in non-Hodgkin's lymphoma. J Clin Oncol. 2001;19:2100-1. doi:10.1200/JCO.2001.19.7.2100.

66. Burrows NP, Jones RR. Yellow nail syndrome in association with carcinoma of the gall bladder. Clin Exp Dermatol. 1991;16:471-3. doi:10.1111/j.13652230.1991.tb01240.x

67. Guin JD, Elleman JH. Yellow nail syndrome. Possible association with malignancy. Arch Dermatol. 1979;115:734-5. doi:10.1001/archderm.1979. 04010060042027.

68. Mambretti-Zumwalt J, Seidman JM, Higano N. Yellow nail syndrome: complete triad with pleural protein turnover studies. South Med J. 1980;73:995-7.

69. Grégoire C, Guiot J, Vertenoeil G, Willems E, Hafraoui K, Corhay JL, et al. Yellow nail syndrome after allogeneic hematopoietic stem cell transplantation in two patients with multiple myeloma. Acta Clin Belg. 2016; 6:1-3. doi:10.1080/17843286.2015.1122872.

70. Gupta S, Samra D, Yel L, Agrawal S. T and B cell deficiency associated with yellow nail syndrome. Scand J Immunol. 2012;75:329-35. doi:10.1111/j.13653083.2011.02653.x

71. Siegelman SS, Heckman BH, Hasson J. Lymphedema, pleural effusions and yellow nails: associated immunologic deficiency. Dis Chest. 1969;56:114-7. doi:10.1378/chest.56.2.114.

72. Woollons A, Darley CR. Yellow nail syndrome following Guillain-Barré syndrome. Clin Exp Dermatol. 1997;22:253-4. doi:10.1111/j.1365-2230.1997. tb01084.x

73. Cockram CS, Richards P. Yellow nails and nephrotic syndrome. Br J Dermatol. 1979;101:707-9. doi:10.1111/j.1365-2133.1979.tb05651.x.

74. Sakiyama T, Shimizu T, Funakoshi T, Saito M. Case of yellow nail syndrome accompanied by nephrotic syndrome. J Dermatol. 2016;43:585-6. doi:10.1111/1346-8138.13239.

75. Dilley JJ, Kierland RR, Randall RV, Shick RM. Primary lymphedema associated with yellow nails and pleural effusions. JAMA. 1968;204:670-3. doi:10.1001/ jama.1968.03140210024005.

76. Noël-Savina E, Paleiron N, Leroyer C, Descourt R. Découverte d'un syndrome des ongles jaunes lors d'une insuffisance thyroïdienne majeure. Rev Pneumol Clin. 2012;68:315-7. doi:10.1016/j.pneumo.2012.06.001.

77. Nakielna EM, Wilson J, Ballon HS. Yellow-nail syndrome: report of three cases. Can Med Assoc J. 1976;115:46-8.

78. Danenberg HD, Eliashar R, Flusser G, Rosenmann E, Chajek-Shaul T. Yellow nail syndrome and xanthogranulomatous pyelonephritis. Postgrad Med J. 1995:71:110-1.

79. David-Vaudey E, Jamard B, Hermant C, Cantagrel A. Yellow nail syndrome in rheumatoid arthritis: a drug-induced disease? Clin Rheumatol. 2004;23:376-8. doi:10.1007/s10067-004-0862-2.

80. Runyon BA, Forker EL, Sopko JA. Pleural-fluid kinetics in a patient with primary lymphedema, pleural effusions, and yellow nails. Am Rev Respir Dis. 1979;119:821-5

81. Bokszczanin A, Levinson Al. Coexistent yellow nail syndrome and selective antibody deficiency. Ann Allergy Asthma Immunol. 2003;91:496-500. doi:10. 1016/S1081-1206(10)61521-9.

82. Vignes S, Carcelain G. Increased surface receptor Fas (CD95) levels on CD4 ${ }^{+}$ lymphocytes in patients with primary intestinal lymphangiectasia. Scand J Gastroenterol. 2009;44:252-6. doi:10.1080/00365520802321220.

83. Mattingly PC, Bossingham DH. Yellow nail syndrome in rheumatoid arthritis: report of three cases. Ann Rheum Dis. 1979;38:475-8.

84. Nakagomi D, Ikeda K, Kawashima H, Kobayashi Y, Suto A, Nakajima H. Bucillamine-induced yellow nail in Japanese patients with rheumatoid arthritis: two case reports and a review of 36 reported cases. Rheumatol Int. 2013;33:793-7. doi:10.1007/s00296-011-2241-z.

85. Mishra AK, George AA, George L. Yellow nail syndrome in rheumatoid arthritis: an aetiology beyond thiol drugs. Oxf Med Case Rep. 2016;2016:3740. doi:10.1093/omcr/omw013.

86. Chiriac A, Brzezinski P, Foia L, Marincu I. Chloronychia: green nail syndrome caused by Pseudomonas aeruginosa in elderly persons. Clin Interv Aging. 2015;10:265-7. doi:10.2147/CIA.S75525.
87. Haneke E. Isolated bullous lichen planus of the nails mimicking yellow nai syndrome. Clin Exp Dermatol. 1983;8:425-8. doi:10.1111/j.1365-2230.1983. tb01806.x.

88. Baran R. Lichen planus of the nails mimicking the yellow nail syndrome. $\mathrm{Br}$ Dermatol. 2000;143:1117-8. doi:10.1046/j.1365-2133.2000.03811.x.

89. Tosti A, Piraccini BM, Cameli N. Nail changes in lichen planus may resemble those of yellow nail syndrome. Br J Dermatol. 2000;142:848-9. doi:10.1046/j. 1365-2133.2000.03460.x

90. Baran R, Rycroft RJG. Occupational abnormalities and contact dermatitis. In: Baran R, de Berker DAR, Holzberg M, Thomas L, editors. Baran and Dawber's diseases of the nails and their management. 4th ed. Oxford: Wiley-Blackwell 2012. p. 443-69.

91. Jiyad Z, Cousins E, Stanton A, Mortimer P. Yellow nail syndrome: a primary lymphatic disorder? Br J Dermatol. 2014;171 Suppl 1:9. doi:10.1111/bjd.12930.

92. Abell E, Samman PD. Yellow nail syndrome treated by intra-lesional triamcinolone acetonide. Br J Dermatol. 1973;88:200-1.

93. Ayres Jr S, Mihan R. Yellow nail syndrome: response to vitamin E. Arch Dermatol. 1973;108:267-8. doi:10.1001/archderm.1973.01620230063024.

94. Williams HC, Buffham R, du Vivier A. Successful use of topical vitamin E solution in the treatment of nail changes in yellow nail syndrome. Arch Dermatol. 1991;127:1023-8. doi:10.1001/archderm.1991.01680060097012.

95. Arroyo JF, Cohen ML. Improvement of yellow nail syndrome with oral zinc supplementation. Clin Exp Dermatol. 1993;18:62-4. doi:10.1111/j.1365-2230. 1993.tb00971.x.

96. Tosti A, Piraccini BM, lorizzo M. Systemic itraconazole in the yellow nail syndrome. Br J Dermatol. 2002;146:1064-7. doi:10.1046/j.1365-2133.2002. 04671.x.

97. Baran R, Thomas L. Combination of fluconazole and alpha-tocopherol in the treatment of yellow nail syndrome. J Drugs Dermatol. 2009;8:276-8.

98. Doncker PD, Pierard GE. Acquired nail beading in patients receiving itraconazole - an indicator of faster nail growth? A study using optical profilometry. Clin Exp Dermatol. 1994;19:404-6. doi:10.1111/j.1365-2230. 1994.tb02693.x.

99. Luyten C, André J, Walraevens C, De Doncker P. Yellow nail syndrome and onychomycosis. Experience with itraconazole pulse therapy combined with vitamin E. Dermatology. 1996;192:406-8.

100. Suzuki M, Yoshizawa A, Sugiyama H, Ichimura Y, Morita A, Takasaki J, et al. A case of yellow nail syndrome with dramatically improved nail discoloration by oral clarithromycin. Case Rep Dermatol. 2011;3:251-8. doi:10.1159/000334734.

101. Imadojemu S, Rubin A. Dramatic improvement of yellow nail syndrome with a combination of intralesional triamcinolone, fluconazole, and sinusitis management. Int J Dermatol. 2015;54:e497-9. doi:10.1111/ijd.12916.

102. Balmforth D, Bille A, Okiror L, Harrsion-Phipps K, Routledge T. Recurrent pleural effusion in yellow nail syndrome successfully treated with video-assisted thoracic surgery: comparison of two surgical strategies in two cases. Gen Thorac Cardiovasc Surg. 2013;61:231-3. doi:10.1007/s11748-012-0125-0.

103. Yamagishi T, Hatanaka N, Kamemura H, Nakazawa I, Hirano Y, Kodaka N, et al. Idiopathic yellow nail syndrome successfully treated with OK-432. Intern Med. 2007:46:1127-30. doi:10.2169/internalmedicine.46.0022.

104. Widjaja A, Gratz KF, Ockenga J, Wagner S, Manns MP. Octreotide for therapy of chylous ascites in yellow nail syndrome. Gastroenterology. 1999;116:1017-8.

105. Makrilakis K, Pavlatos S, Giannikopoulos G, Toubanakis C, Katsilambros N. Successful octreotide treatment of chylous pleural effusion and lymphedema in the yellow nail syndrome. Ann Intern Med. 2004;141:246-7. doi:10.7326/0003-4819-141-3-200408030-00027.

106. Lotfollahi L, Abedini A, Alavi Darazam I, Kiani A, Fadaii A. Yellow nail syndrome: report of a case successfully treated with octreotide. Tanaffos. 2015;14:67-71.

107. Hillerdal G. Yellow nail syndrome: treatment with octreotide. Clin Respir J. 2007;1:120-1. doi:10.1111/j.1752-699X.2007.00022.x

108. Nakabayashi H, Sagara H, Usukura N, Yoshimitsu K, Imamura T, Seta T. Effect of somatostatin on the flow rate and triglyceride levels of thoracic duct lymph in normal and vagotomized dogs. Diabetes. 1981;30:440-5. doi:10. 2337/diab.30.5.440.

109. Wahid ST, Marbach P, Stolz B, Miller M, James RA, Ball SG. Partial tachyphylaxis to somatostatin (SST) analogues in a patient with acromegaly: the role of SST receptor desensitisation and circulating antibodies to SST analogues. Eur J Endocrinol. 2002:146:295-302. doi:10.1530/eje.0.1460295.

110. Cheville AL, McGarvey CL, Petrek JA, Russo SA, Taylor ME, Thiadens SR. Lymphedema management. Semin Radiat Oncol. 2003:13:290-301. doi:10. 1016/S1053-4296(03)00035-3. 
111. Lasinski BB, McKillip Thrift K, Squire D, Austin MK, Smith KM, Wanchai A, et al. A systematic review of the evidence for complete decongestive therapy in the treatment of lymphedema from 2004 to 2011. PM R. 2012;4:580-601. doi:10.1016/j.pmrj.2012.05.003.

112. International Society of Lymphology. The diagnosis and treatment of peripheral lymphedema: 2013 consensus document of the International Society of Lymphology. Lymphology. 2013:46:1-11.

113. Vignes S, Arrault M. Prise en charge des patients atteints de lymphœedème In: Simon D, Traynard PY, Bourdillon F, Gagnayre R, Grimaldi A, editors. Education Thérapeutique. Paris: Elsevier Masson; 2013. p. 261-70.

114. DeCastro A, Mims L, Hueston WJ. Rhinosinusitis. Prim Care. 2014;41:47-61. doi:10.1016/j.pop.2013.10.006.

115. Rudmik L, Soler ZM. Medical therapies for adult chronic sinusitis: a systematic review. JAMA. 2015;314:926-39. doi:10.1001/jama.2015.7544.

116. Khalil HS, Nunez DA. Functional endoscopic sinus surgery for chronic rhinosinusitis. Cochrane Database Syst Rev. 2006;3:CD004458. doi:10.1002/ 14651858.CD004458.pub2.

Submit your next manuscript to BioMed Central and we will help you at every step:

- We accept pre-submission inquiries

- Our selector tool helps you to find the most relevant journal

- We provide round the clock customer support

- Convenient online submission

- Thorough peer review

- Inclusion in PubMed and all major indexing services

- Maximum visibility for your research

Submit your manuscript at www.biomedcentral.com/submit
Biomed Central 